ISSN: 1641-4713; e-ISSN: 2081-1160

DOI: https://doi.org/10.36551/2081-1160.2021.28.31-54

\title{
Política y represión. Un estudio empírico del reclutamiento de intendentes en la provincia de Buenos Aires durante la última dictadura cívico-militar (Argentina, 1976-1983)
}

\author{
Politics and repression. An empirical study of the recruitment of mayors \\ in the province of Buenos Aires during the last civil-military dictatorship \\ (Argentina, 1976-1983)
}

Paula Vera Canelo

Facultad Latinoamericana de Ciencias Sociales (FLACSO) Consejo Nacional de Investigaciones Científicas y Técnicas (CONICET), Argentina

Universidad de Buenos Aires (UBA), Argentina ORCID iD: https://orcid.org/0000-0001-8190-8915

E-mail: pvcanelo@yahoo.com

Recepción: 28.04.2021

Aprobación: 3.09 .2021

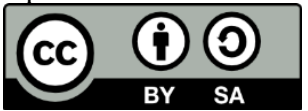

Resumen: El artículo realiza un estudio empírico del reclutamiento de intendentes en la provincia de Buenos Aires durante la última dictadura cívico-militar argentina. Primero, analiza la evolución del proceso de militarización del reclutamiento de las máximas autoridades municipales entre 1976 y 1983. Segundo, estudia el vínculo entre designación de autoridades políticas y tres factores considerados estratégicos desde el punto de vista militar: la densidad poblacional, la población industrial y la población estudiantil superior o universitaria, en cada municipio. Finalmente, realiza un balance de las características generales de los intendentes bonaerenses, en términos de procedencia, distribución, experiencia previa y estabilidad entre 1976 y 1983.

Palabras clave: intendentes, municipios, reclutamiento, dictadura cívico-militar, provincia de Buenos Aires, Argentina

Abstract: The article carries out an empirical study of the recruitment of mayors in the province of Buenos Aires during the last civil-military dictatorship in Argentina. First, it analyses the evolution of the process of militarisation of the recruitment of the highest municipal authorities between 1976 
and 1983. Second, it studies the link between the designation of political authorities and three factors considered strategic from a military point of view: population density, industrial population and higher education or university student population in each municipality. Finally, it takes stock of the general characteristics of Buenos Aires mayors, in terms of origin, distribution, previous experience and stability between 1976 and 1983.

Keywords: mayors, municipalities, recruitment, civil-military dictatorship, province of Buenos Aires, Argentina

\section{INTRODUCCIÓN ${ }^{1}$}

A partir de mediados de la década de 2000, en la Argentina y en otros países latinoamericanos se asiste a la renovación de los estudios sobre las dictaduras de los años sesenta y setenta, y a la reformulación tanto de temas y problemas, como de métodos y disciplinas, en un ciclo caracterizado por la heterogeneidad $\left(\right.$ Canelo, 2016) ${ }^{2}$. En este contexto de cambios, una de las líneas de trabajo más fructíferas es la de los estudios sobre actitudes y comportamientos sociales, y los trabajos sobre participación o trama civil de las dictaduras. Los primeros analizaron la "micropolítica" local (O’Donnell, 1997) estudiando las redes formadas por entidades intermedias o fuerzas vivas, como asociaciones vecinales, de fomento, clubes de barrio, etc., que otorgaron consenso y legitimación a las dictaduras ${ }^{3}$. Los segundos enfatizaron, más que el consenso, la colaboración concreta de los civiles como funcionarios y/o ideólogos o intelectuales ${ }^{4}$.

En la mayoría de los casos, estas valiosas líneas de investigación comparten lo que denominamos mainstream interpretativo sobre la última dictadura argentina (Canelo, 2016), que enfatiza la importancia de analizar a los civiles más que a los militares, y a los objetivos económicos más que a los políticos o represivos. Así, tanto el actor predominante en la experiencia, las Fuerzas Armadas, como la autonomía y relevancia de sus objetivos políticos y represivos, fueron relativamente soslayados como clave interpretativa principal. Son escasos aún,

\footnotetext{
${ }^{1}$ Este artículo no hubiera sido posible sin los aportes de Juan Pablo Kryskowski, Darío Rubinstein, Sergio Eissa y Fernando Sabuda, quien tuvo a su cargo la elaboración de la cartografía.

${ }^{2}$ Entre una abundante producción, es posible mencionar aquí nuevas perspectivas sobre memorias y exilios (Araujo et al., 2013; Crenzel, 2014; Da Silva Catela \& Jelin, 2002; Feld \& Salvi, 2019; Jensen \& Lastra, 2014; Markarian, 2006; Viz Quadrat, 2011), la violencia política y la represión (Águila et al., 2016; Franco, 2012; McSherry, 2005), las derechas políticas (Bohoslavsky et al., 2019; Morresi, 2019; Vicente, 2015), o la militancia armada (Carnovale, 2011; Confino, 2015).

${ }^{3}$ Sólo como ejemplos, para el caso argentino, González Bombal (2015), Lvovich (2010) y Rodríguez (2009); para el uruguayo, Marchesi (2009) y Yaffé (2012); para el brasileño, Rollemberg \& Viz Quadrat (2010); y para el chileno, Valdivia Ortiz de Zárate et al. (2012).

${ }^{4}$ Por ejemplo, Bohoslavsky (2015) y Muleiro (2011).
} 
por ejemplo, los estudios empíricos y/o de casos que analicen las estructuras burocrático-militares, los procesos de militarización de los Estados y los gobiernos en sus diferentes niveles, las zonas grises entre política y represión, etc. ${ }^{5}$

El presente artículo analiza el vínculo entre objetivos político-gubernamentales y objetivos represivos de la dictadura cívico-militar argentina. Para ello, realiza un estudio empírico del reclutamiento de intendentes en la provincia de Buenos Aires -en adelante, PBA-, la más importante de la Argentina, entre 1976 y 1983.

Desde el punto de vista metodológico y de escala, los estudios que han abordado el caso bonaerense durante la dictadura lo han hecho, en general, desde perspectivas cualitativas -entrevistas, análisis de documentos y/o archivos de organismos represivos como, por ejemplo, el de la ex Dirección de Inteligencia de la Policía de la PBA o DIPBA, etc.-, sin avanzar sobre los aspectos cuantitativos. Asimismo, para el período, la unidad municipal ha tendido a predominar sobre la provincial $^{6}$.

El estudio de la PBA reúne la mayor de las relevancias con un alto grado de dificultad. Por un lado, es la provincia más importante de la Argentina, la más grande en extensión y en habitantes, con la mayor complejidad y relevancia política. Por otro, su estudio durante el período elegido se enfrenta con importantes carencias documentales, como falta de sistematicidad, dispersión, inaccesibilidad e incluso destrucción deliberada de archivos (Canelo \& Ippolito-O’Donnell, 2018).

Este artículo ha sido realizado a partir de un conjunto amplio y heterogéneo de fuentes, entre ellas el Censo Nacional de Población y Vivienda de 1980, el Censo Nacional Económico de 1974 y el Boletín Oficial de la PBA. La sistematización informativa permitió la construcción de la base de datos "Municipios y autoridades políticas bonaerenses PRN 1976/1983", principal herramienta de esta investigación ${ }^{7}$.

A continuación, se explica la relevancia política y represiva de la PBA durante la última dictadura; luego, se analiza la evolución del proceso de milita-

\footnotetext{
${ }^{5}$ Algunas excepciones son Águila (2017), Águila et al. (2016), Canelo (2019), Castiglione (1992), Scocco et al. (2021), entre otros.

${ }^{6}$ Solo como ejemplos, Ballester (2014), Catoira (2013) y Lvovich (2010).

${ }^{7}$ La base en Excel releva algunas variables sobre los 406 intendentes que ocuparon dicho cargo en la PBA en algún momento entre 1976 y 1983 (procedencia, fuerza, etc.) y otras sobre los 125 municipios de la PBA (densidad poblacional, población total, \% de población ocupada en actividades industriales, PEA estimada, \% de población que asiste a nivel educativo superior o universitario, etc.). La cartografía fue realizada mediante un sistema de información geográfica -SIG- de base vectorial y código abierto QGIS que vincula los datos almacenados en una tabla de atributos con las unidades espaciales o partidos de la PBA.
} 
rización ${ }^{8}$ del reclutamiento de las máximas autoridades municipales entre 1976 y 1983. En el tercer apartado se estudia el vínculo entre la designación de autoridades políticas y los tres factores considerados estratégicos desde el punto de vista militar: la densidad poblacional, la población industrial y la población estudiantil superior o universitaria. Finalmente, se realiza un balance de las características generales de los intendentes bonaerenses, en términos de procedencia, distribución, experiencia previa y estabilidad entre 1976 y 1983.

\section{LA PBA DURANTE LA ÚLTIMA DICTADURA CÍVICO-MILITAR: RELEVANCIA POLÍTICA Y REPRESIVA.}

MAPA 1: División POLÍTICA DE LA PBA DURANTE LA DiCTADURA CíviCO-MILITAR.

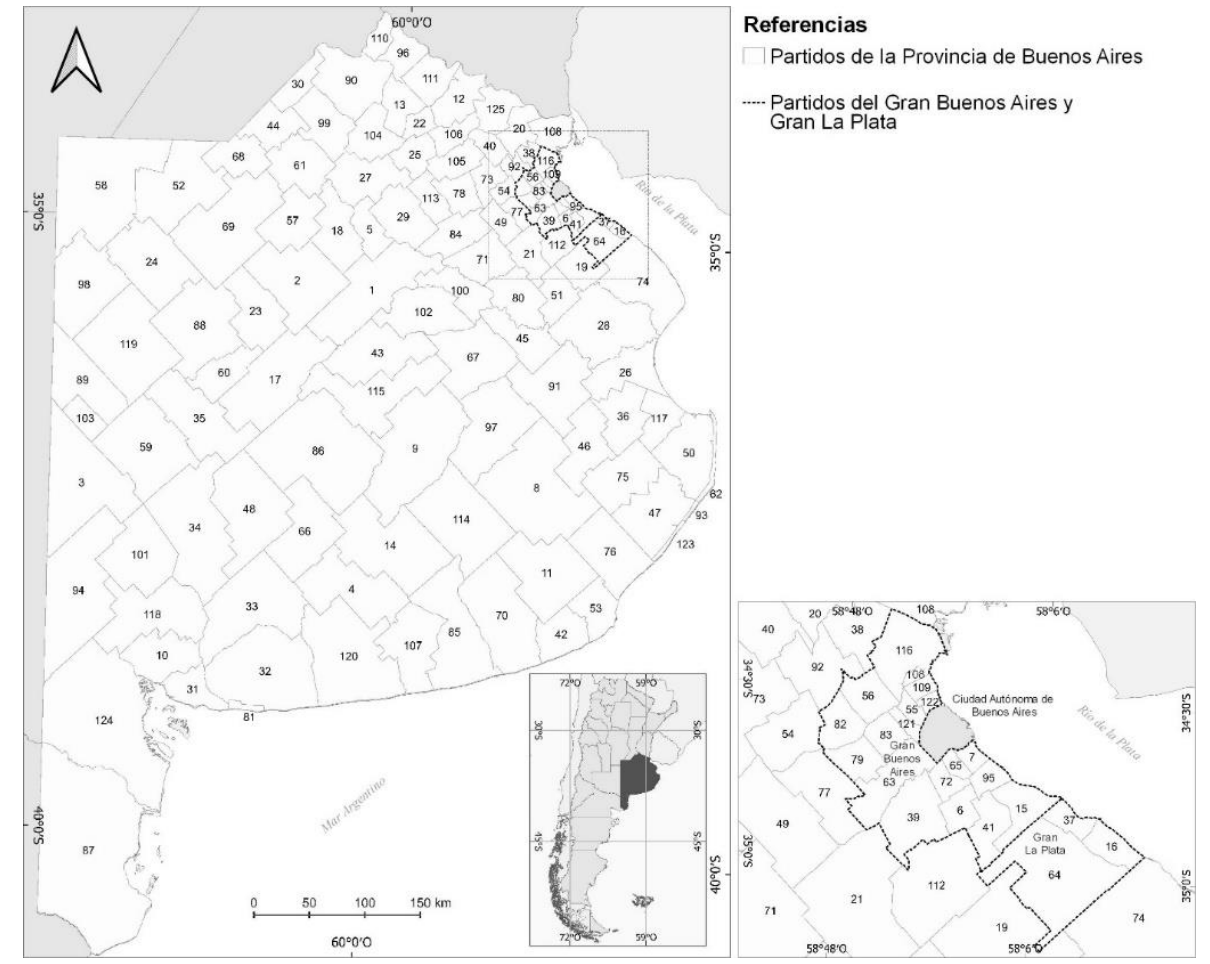

Fuente: Elaboración propia en base a cartografía del Instituto Geográfico Nacional.

\footnotetext{
${ }^{8}$ En este artículo el indicador principal de militarización de las autoridades políticas de un municipio es la procedencia militar o de las fuerzas de seguridad del intendente.
} 


\section{TABLA 1: REFERENCIAS.}

\begin{tabular}{|c|c|}
\hline 1 & 25 de Mayo \\
\hline 2 & 9 de Julio \\
\hline 3 & Adolfo Alsina \\
\hline 4 & Adolfo Gonzales Chaves \\
\hline 5 & Alberti \\
\hline 6 & Almirante Brown \\
\hline 7 & Avellaneda \\
\hline 8 & Ay acucho \\
\hline 9 & Azul \\
\hline 10 & Bahía Blanca \\
\hline 11 & Balcarce \\
\hline 12 & Baradero \\
\hline 13 & Bartolomé Mitre \\
\hline 14 & Benito Juárez \\
\hline 15 & Berazategui \\
\hline 16 & Berisso \\
\hline 17 & Bolívar \\
\hline 18 & Bragado \\
\hline 19 & Brandsen \\
\hline 20 & Campana \\
\hline 21 & Cañuelas \\
\hline 22 & Capitán Sarmiento \\
\hline 23 & Carlos Casares \\
\hline 24 & Carlos Tejedor \\
\hline 25 & Carmen de Areco \\
\hline 26 & Castelli \\
\hline 27 & Chacabuco \\
\hline 28 & Chascomús \\
\hline 29 & Chivilcoy \\
\hline 30 & Colon \\
\hline 31 & Cnel. L. Rosales \\
\hline 32 & Coronel Dorrego \\
\hline 33 & Coronel Pringles \\
\hline 34 & Coronel Suarez \\
\hline 35 & Daireaux \\
\hline 36 & Dolores \\
\hline 37 & Ensenada \\
\hline 38 & Escobar \\
\hline 39 & Esteban Echeverría \\
\hline 40 & Exaltación de la Cruz \\
\hline 41 & Florencio Varela \\
\hline 42 & General Alvarado \\
\hline
\end{tabular}

\begin{tabular}{|c|c|c|c|}
\hline 43 & General Alvear & 85 & Necochea \\
\hline 44 & General Arenales & 86 & Olavarría \\
\hline 45 & General Belgrano & 87 & Patagones \\
\hline 46 & General Guido & 88 & Pehuajó \\
\hline 47 & General Juan Madariaga & 89 & Pellegrini \\
\hline 48 & General La Madrid & 90 & Pergamino \\
\hline 49 & General Las Heras & 91 & Pila \\
\hline 50 & General Lavalle & 92 & Pilar \\
\hline 51 & General Paz & 93 & Pinamar \\
\hline 52 & General Pinto & 94 & Puan \\
\hline 53 & General Puey rredón & 95 & Quilmes \\
\hline 54 & General Rodríguez & 96 & Ramallo \\
\hline 55 & General San Martin & 97 & Rauch \\
\hline 56 & General Sarmiento & 98 & Rivadavia \\
\hline 57 & General Viamonte & 99 & Rojas \\
\hline 58 & General Villegas & 100 & Roque Pérez \\
\hline 59 & Guaminí & 101 & Saavedra \\
\hline 60 & Hipólito Irigoy en & 102 & Saladillo \\
\hline 61 & Junín & 103 & Salliqueló \\
\hline 62 & La Costa & 104 & Salto \\
\hline 63 & La Matanza & 105 & San Andrés de Giles \\
\hline 64 & La Plata & 106 & San Antonio de Areco \\
\hline 65 & Lanús & 107 & San Cay etano \\
\hline 66 & Laprida & 108 & San Fernando \\
\hline 67 & Las Flores & 109 & San Fernando \\
\hline 68 & Leandro N. Alem & 110 & San Isidro \\
\hline 69 & Lincoln & 111 & San Nicolás \\
\hline 70 & Lobería & 112 & San Pedro \\
\hline 71 & Lobos & 113 & San Vicente \\
\hline 72 & Lomas de Zamora & 114 & Suipacha \\
\hline 73 & Luján & 115 & Tandil \\
\hline 74 & Magdalena & 116 & Tapalqué \\
\hline 75 & Maipú & 117 & Tigre \\
\hline 76 & Mar Chiquita & 118 & Tordillo \\
\hline 77 & $\mathrm{M} \operatorname{arcos} \mathrm{Paz}$ & 119 & Tornquist \\
\hline 78 & Mercedes & 120 & Trenque Lauquen \\
\hline 79 & Merlo & 121 & Tres Arroyos \\
\hline 80 & Monte & 122 & Tres de Febrero \\
\hline 81 & Monte Hermoso & 123 & Vicente López \\
\hline 82 & Moreno & 124 & Villa Gesell \\
\hline 83 & Morón & 125 & Villarino \\
\hline 84 & Navarro & 126 & Zárate \\
\hline
\end{tabular}

Nota: San Fernando no posee unidad espacial, por lo que está representado con 2 números. 
En la PBA los municipios no equivalen a localidades, sino a departamentos o partidos, constituyendo la unidad política de gobierno local de menor nivel territorial. Al comenzar la dictadura, los municipios bonaerenses eran 121, y al finalizar, 125, debido a la creación, por Ley $\mathrm{N}^{0} 9.024$ de 1978, de los municipios urbanos De la Costa, Pinamar, Villa Gesell y Monte Hermoso.

Según el Censo 1980 (INDEC, 1982) la superficie total de la PBA era de $307.571 \mathrm{~km}^{2}$, con una densidad poblacional promedio de 35,3 habitantes $/ \mathrm{km}^{2}$. Esto encubría importantes asimetrías y heterogeneidades. Por un lado, zonas urbanas densamente pobladas 9 , entre ellas el llamado Gran Buenos Aires -en adelante, GBA-, que con una superficie de $3.680 \mathrm{~km}^{2}$ poseía una densidad de $1.859,6 \mathrm{hab} / \mathrm{km}^{2}$, y donde se ubicaban partidos con altísimas densidades poblacionales, como Lanús -10.377,33-, Tres de Febrero -7.509,22- o Vicente López -7.463,38- ${ }^{10}$. También el llamado Gran La Plata - en adelante, GLP-, formado por La Plata, Berisso y Ensenada, poseía densidades poblacionales cercanas a 500. Por otro lado, el resto de la PBA tenía una densidad de sólo 13,2 habitantes $/ \mathrm{km}^{2}$, e incluía zonas rurales con bajísima densidad, como General Lavalle -0,5- o Pila -0,8(INDEC, 1982, pp. 2 y ss.)

En 1976, la designación de las autoridades políticas municipales fue un importante desafío para la dictadura, dada su importancia estratégica. Desde el punto de vista político, la escala reducida del municipio lo volvía el espacio ideal para gestar a la nueva dirigencia heredera del Proceso, consustanciada con los problemas cotidianos de una ciudadanía municipal, apolítica y local; y también el ámbito adecuado para, en un futuro lejano y de ser necesario, dar los primeros pasos hacia algún sistema de elecciones escalonadas (Canelo, 2016).

Los intendentes debían cumplir funciones políticas diferenciadas de las de otros funcionarios gubernamentales. Tal como señalaban el entonces presidente de la Nación y miembro de la Junta Militar, el general Jorge Rafael Videla, y su Ministro del Interior, el general Albano Harguindeguy, debía lograrse una "relación más directa" entre gobernantes y gobernados (La Nación, 16/4/1977) y privilegiarse a individuos con estrecha vinculación con las asociaciones locales y amplio reconocimiento en la comunidad (González Bombal, 1988; Yannuzzi, 1996).

\footnotetext{
${ }^{9}$ Adoptamos aquí la definición de urbano para referirnos a aquellos municipios o unidades territoriales con densidad de población mayor a 150 habitantes $/ \mathrm{km}^{2}$, mientras que los rurales son aquellos que presentan densidades menores (OCDE, 2011).

${ }^{10}$ Dado que el Censo 1980 no presenta datos del GBA sobre densidad poblacional discriminados por partidos, estos datos fueron reconstruidos sobre datos de población total y superficies de cada partido, considerando los cambios en la división política.
} 
La relevancia política de la PBA también se manifestó en la designación como gobernador del general Ibérico Saint Jean; de alto perfil público, lideró el llamado Grupo La Plata, una de las usinas de pensamiento que redactó el primer plan político de la dictadura titulado Un nuevo ciclo histórico argentino: del Proceso de Reorganización Nacional a la Tercera República, de octubre de 1976 (Grupo La Plata, 1976).

El poder político bonaerense estuvo fuertemente conectado con el poder represivo, a cuyo frente se encontraba, hacia 1976, el general Ramón Camps, jefe de la Policía Bonaerense y paradigmático exponente del terror de Estado. El tendido represivo que atravesó a la PBA incluyó al llamado circuito Camps, que se extendió por nueve partidos de la zona metropolitana de la PBA, integrado por alrededor de 29 Centros Clandestinos de Detención, 10 ubicados en la ciudad de La Plata (Muleiro, 2011).

La PBA era considerada de "alta prioridad" en la "lucha contra la subversión”, al menos desde 1975, ya que la inteligencia militar identificaba allí el accionar de dos "grandes" frentes de las "Organizaciones Político-Militares" "PRT-ERP y Montoneros" (Comando General del Ejército, 1975, p. 60, mapa 281700). A partir del golpe, bajo el concepto de "conducción centralizada y ejecución descentralizada y flexible” (La Nación, 20/4/1977), el Ejército se reservó "la responsabilidad primaria en la dirección de las operaciones contra la subversión", la conducción de "la comunidad informativa" y la "vigilancia de frontera" en toda la Argentina; mientras que la Armada y la Fuerza Aérea asignaron elementos de "apoyo" constituyendo "fuerzas conjuntas" (D’Andrea Mohr, 1999, pp. 55 y 98; Mittelbach \& Mittelbach, 2000, pp. 16 y ss.). Las fuerzas de seguridad -Gendarmería Nacional, Prefectura Nacional, Policía Federal y policías provinciales- estaban bajo "control operacional" de los Comandos de Zona (Mittelbach \& Mittelbach, 2000, p. 23).

En abril de 1977, el Estado Mayor General del Ejército-EMGE- publicó un extenso documento denominado La subversión en la Argentina, donde detallaba los orígenes y evolución del "enemigo subversivo". La amplitud y profundidad de la estrategia del enemigo requería un plan de acción capilar de control del territorio y de la población -"sujeto" y "objeto de la subversión"-, pero especialmente del sector urbano industrial y del estudiantil ${ }^{11}$ :

\footnotetext{
${ }^{11}$ Es amplia la bibliografía que destaca la importancia del sector industrial y estudiantil como blancos de la represión dictatorial en la Argentina (Frontalini \& Caiati, 1984; Mignone, 1991; Mignone \& Conte Mc Donnell, 2006). La PBA, especialmente el GBA y el GLP, fueron las zonas más castigadas: las víctimas nacidas en la Ciudad de Buenos Aires y la PBA representaron el 53\% del total; fue en el GBA y el GLP donde se produjo la mayor cantidad de hechos represivos (Ministerio de Justicia, 2021).
} 
las BDSM $^{12}$ coinciden en la importancia que dan a las concentraciones urbanas, en especial fabriles, como centro de gravedad para sus actividades, basando su éxito en el logro de la captación masiva del sector laboral. El PRT-ERP que inicialmente tuvo su centro de gravedad bien definido en la actividad rural, modificó su actitud y colocó a ésta en un mismo nivel que la acción urbana (hoy) las bandas buscaron llevar su centro de gravedad geográfico sobre CORDOBA, Arco Industrial Ribereño del PARANA, Gran Bs. As. y La Plata (EMGE, 1977, mayúsculas en el original).

DE LA MILITARIZACIÓN A LA CONVERGENCIA CÍVICO-MILITAR: 1976, 1981 Y 1983.

En 1976, la imposición del orden marcial sobre el territorio nacional y la población fue un objetivo central, con la consecuente militarización de las intendencias bonaerenses (Mapa 2).

MaPA 2: PRocedenCIA DE LOS INTENDENTES POR MUNICIPIO. PBA, 1976.

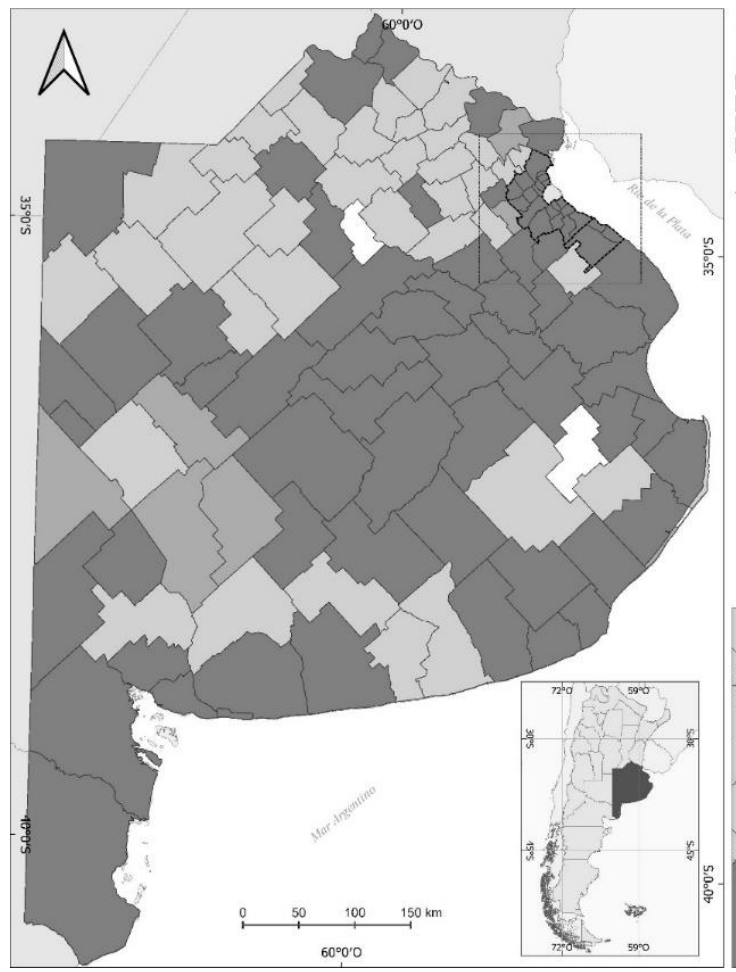

Referencias

Procedencia en 1976 Militar

Fuerzas de Seguridad

$\square$ Civil

$\square$ Sin datos Gran La Plata
Gran Buenos Aires y

Fuente: Elaboración propia.

12 BDSM: Bandas de Delincuentes Subversivos Marxistas. 
Entre los primeros intendentes designados o confirmados luego del golpe, los miembros de las Fuerzas Armadas o de seguridad eran mayoría: el 62\% eran militares, en general del Ejército, y el 6\% pertenecían a alguna de las fuerzas de seguridad. En forma coincidente con el diagnóstico que realizaba el EMGE sobre la "situación de la subversión", todo el GBA, todo el GLP y en casi todos los municipios costeros y ribereños -con la excepción de Necochea y San Cayetano sobre el Atlántico, y de San Pedro y Baradero sobre el Paraná- las intendencias fueron ocupadas por militares. Esta militarización también fue muy importante en la gran franja horizontal rural del centro de la PBA.

Sólo el 32\% de las intendencias de los municipios fueron ocupadas por civiles. La mayoría tenía experiencia en el ejercicio del mismo cargo y pertenecía a partidos políticos tradicionales: un $60 \%$ al Partido Justicialista -varios intendentes bonaerenses fueron confirmados temporariamente en su cargo luego del golpe- y un 21\% a la Unión Cívica Radical (Canelo \& Kryskowski, 2021).

Hacia 1978 la presencia de militares al frente de las intendencias bonaerenses aún era muy elevada en relación con el nivel nacional, donde sólo ocupaban entre un $10 \%$ y un $12 \%$ de las intendencias (Canelo \& Kryskowski, 2021). Sin embargo, durante 1979 se producen numerosos relevos, especialmente entre los intendentes militares de la Zona 1, como consecuencia de la asunción del general Jorge Olivera Rovere como Jefe del Cuerpo I, en reemplazo del general Suarez Mason, y también como producto del lento pero persistente declive del escenario de la guerra entre los criterios de legitimación de la dictadura.

En 1981 la desmilitarización de las autoridades políticas bonaerenses ya era una tendencia clara (Mapa 3).

Durante 1981 se produce el ascenso a las más altas esferas del poder gubernamental de lo que en otro trabajo (Canelo, 2016) llamamos fracción politicista del Ejército, que veía en el acercamiento con los civiles una salida a la ya evidente crisis en la que había caído la dictadura argentina. Con el reemplazo de Videla por Viola en la Presidencia de la Nación, y el de Saint Jean por el general de división Oscar Gallino en la gobernación de la PBA, se inicia un proceso de designaciones civiles en las intendencias bonaerenses, que se acentuará con el posterior nombramiento como gobernador del civil Jorge Aguado, un estrecho colaborador de Saint Jean.

Este avance de la llamada convergencia cívico-militar, que también se constata en otros niveles de gobierno, como gobernaciones y gabinetes (Canelo, 2013, 2016), comienza a mostrar a las intendencias de la PBA con un peso de civiles similar a las del resto del país. En la PBA sólo quedan nueve municipios -el 7,2\%-en manos de miembros del Ejército. 
MAPA 3: PRocedenCIA DE LOS INTENDENTES POR MUNICIPIO. PBA, 1981.

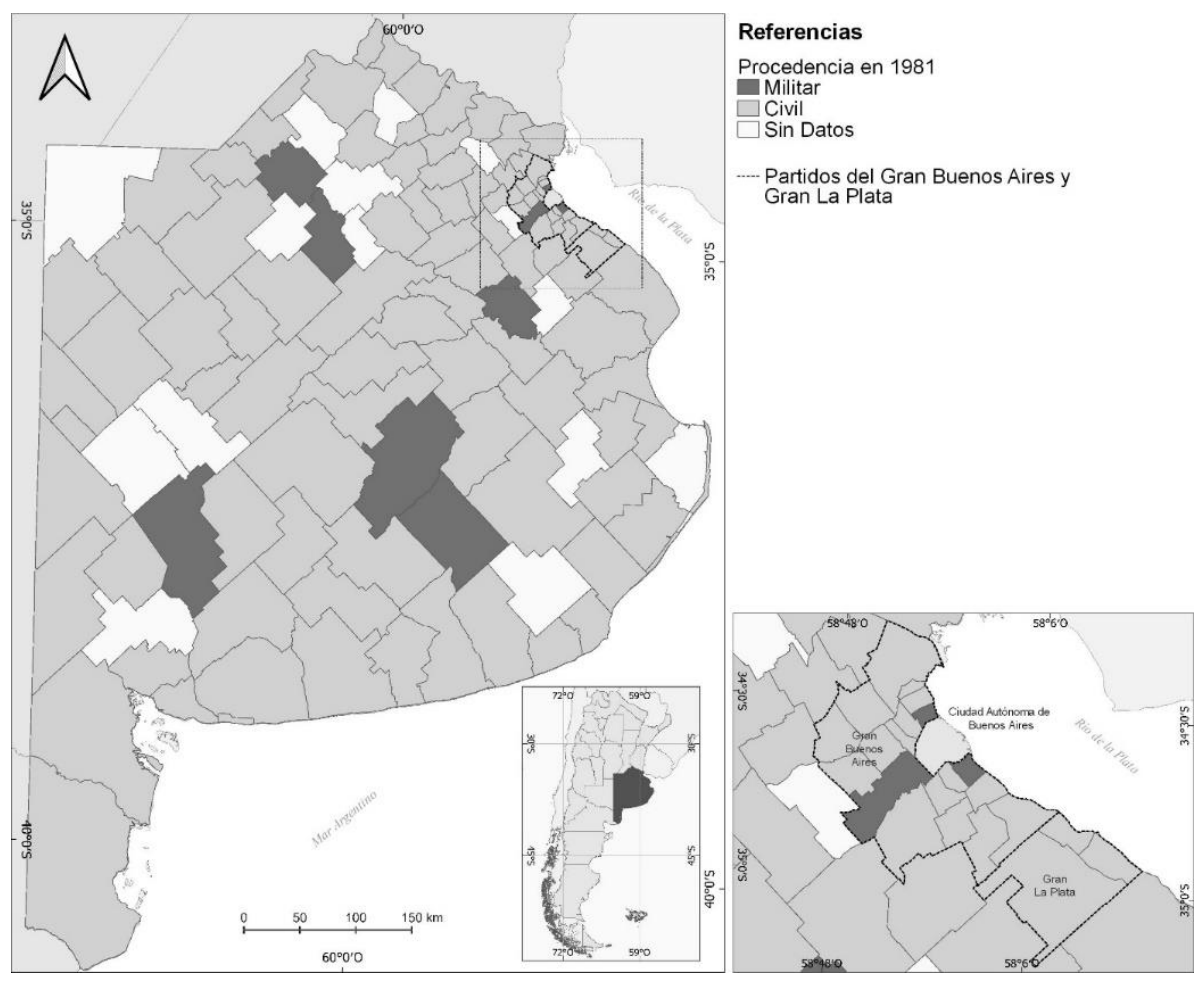

Fuente: Elaboración propia.

Frente a este retroceso de las Fuerzas Armadas en el ejercicio del poder político local, los municipios que permanecen militarizados son Bragado, Vicente López y La Matanza -los únicos que sólo tuvieron intendentes militares, sobre los que volveremos más adelante-, Avellaneda -ubicada en el GBA, con alta densidad poblacional e importante peso industrial-, y Azul, Coronel Suarez, Junín, San Miguel del Monte y Tandil, todos municipios rurales. La persistente militarización de las intendencias de Tandil y Azul puede estar vinculada con la ubicación en dichos municipios de importantes guarniciones militares, entre ellas la Guarnición Militar Azul, que en 1974 había sido objeto de un intento de copamiento por militantes del ERP. 
MAPA 4: PROCEDENCIA DE LOS INTENDENTES POR MUNICIPIO. PBA, 1983.

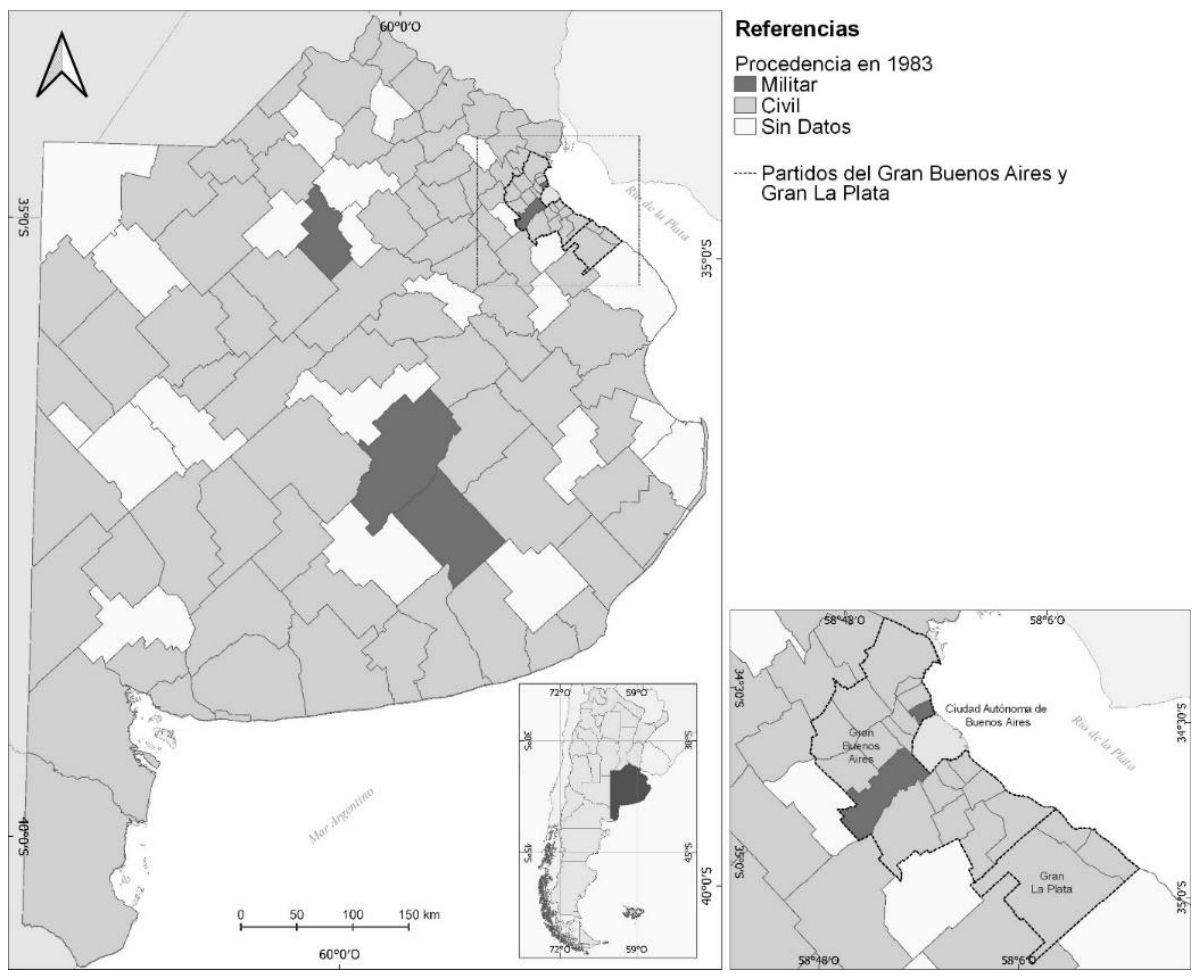

Fuente: Elaboración propia.

Hacia 1983, la desmilitarización de las intendencias de la PBA está consolidada, anticipando la retirada de la dictadura tras la derrota en la guerra de Malvinas contra Gran Bretaña y el progresivo proceso de entrega del poder a los civiles (Canelo, 2016). Las intendencias controladas por militares se habían reducido a sólo un 4\% del total: Bragado, Vicente López y La Matanza, Azul y Tandil.

\section{FACTORES ESTRATÉGICOS DE LA MILITARIZACIÓN.}

A continuación, los Mapas 5, 6 y 7 muestran la asociación entre designación de intendentes militares y tres de los factores considerados estratégicos para las Fuerzas Armadas: la densidad poblacional, el porcentaje de población industrial y el porcentaje de población asistente a algún nivel educativo universitario o superior, en cada municipio. 
MAPA 5: DENSIDAD POBLACIONAL Y PROCEDENCIA DE LOS INTENDENTES MUNICIPALES. PBA, 1976.

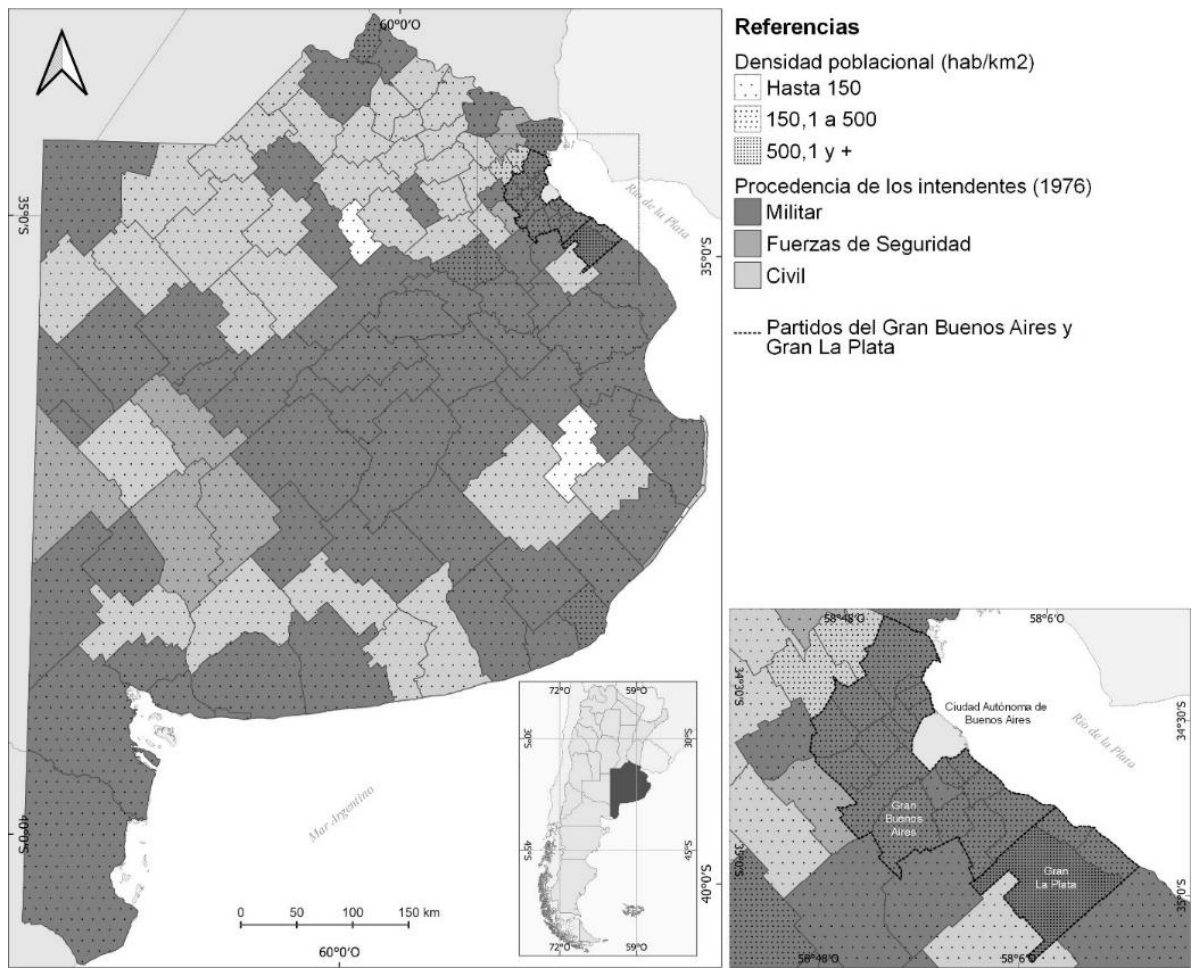

Nota: El Censo 1980 (INDEC, 1982) no desagrega por municipio los datos sobre densidad poblacional del GBA; a todos se les asignó el valor censal máximo $\left(500,1 \mathrm{y}+\mathrm{hab} / \mathrm{km}^{2}\right)$.

Fuente: Elaboración propia en base a INDEC (1982).

El Mapa 5 muestra un fuerte vínculo entre la procedencia de los intendentes y la densidad poblacional. Todos los municipios urbanos -con excepción de Escobar y Pilar- fueron puestos en manos de intendentes militares, incluido todo el GBA con densidades mayores a 500 habitantes $/ \mathrm{km}^{213}$ y todo el GLP -con densidades cercanas a 500,1 y más-, además de todos los costeros y ribereños señalados más arriba. Por el contrario, en las zonas rurales y de menor densidad poblacional fueron designados intendentes civiles.

El Mapa 6 muestra el vínculo existente, en cada municipio, entre la población ocupada en actividades industriales y la procedencia de los intendentes:

\footnotetext{
${ }^{13}$ San Fernando es una excepción en este grupo. La presencia del Apostadero Naval San Fernando en este municipio debe haber incidido en la designación de un intendente militar.
} 
MAPA 6: POBLACIÓN OCUPADA EN ACTIVIDADES INDUSTRIALES (EN \%) Y PROCEDENCIA DE LOS INTENDENTES MUNICIPALES. PBA, 1976.

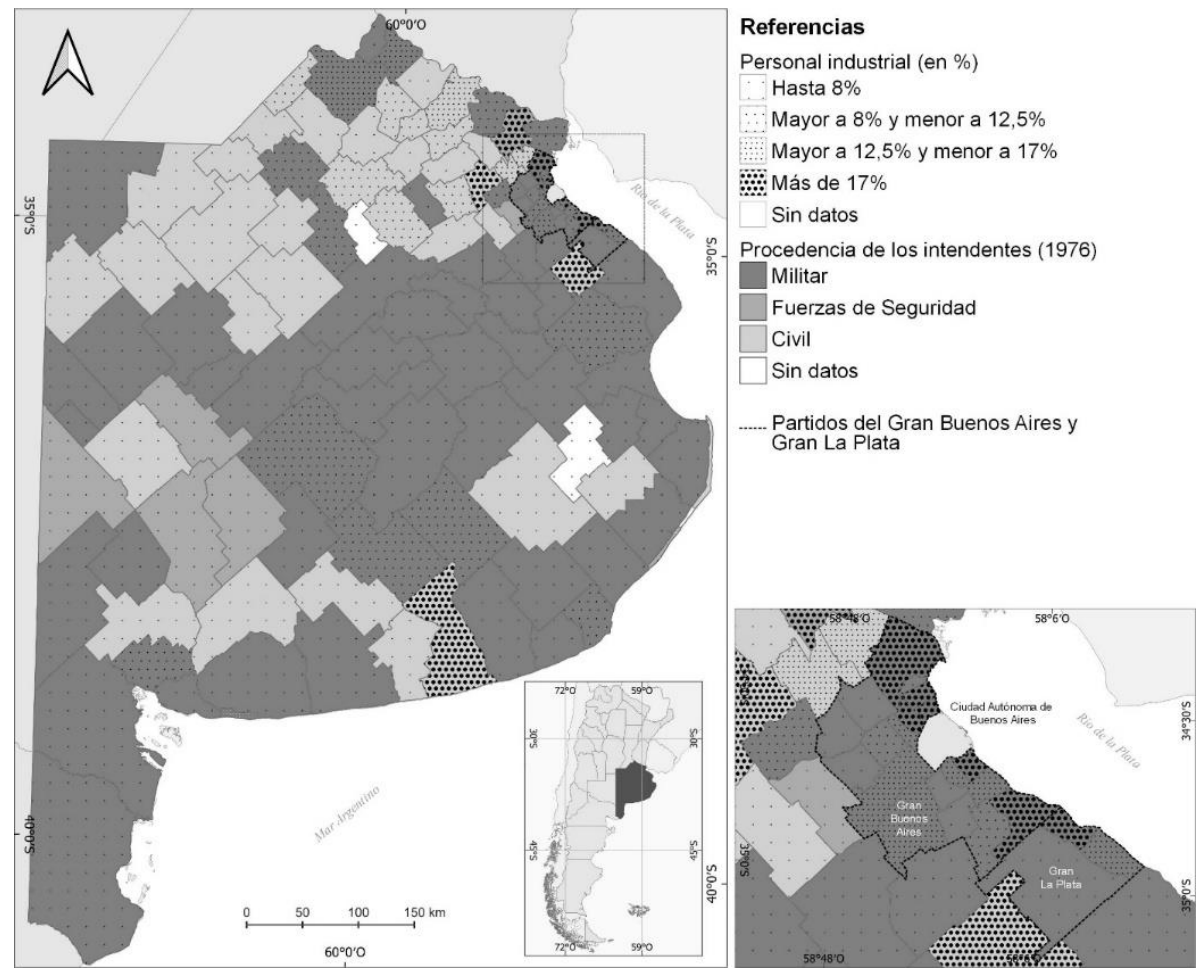

Nota: El Censo Económico 1974 (INDEC, 1974) desagrega por municipio unas pocas variables. Para construir el mapa se elaboró un indicador propio -\% de población ocupada en actividades industriales - combinando la variable "total de personal ocupado en actividades industriales" (INDEC, 1974, pp. 49-88) con una estimación de cada PEA local sobre datos de población del Censo 1970 (INDEC, 1982).

Fuente: Elaboración propia en base a INDEC $(1974,1982)$.

Hacia 1974 sólo 22 municipios bonaerenses presentan un porcentaje de población ocupada en actividades industriales más alto que el promedio provincial $-12,53 \%$ - (Cuadro 1). 
CUADRO 1: MUNICIPIOS CON \% DE POBLACIÓN INDUSTRIAL MAYOR AL PROMEDIO PROVINCIAL

(PBA).

\begin{tabular}{|l|c|c|c|c|}
\hline Municipio & $\begin{array}{c}\text { GBA o } \\
\text { GLP }\end{array}$ & $\begin{array}{c}\text { Procedencia } \\
\text { intendente en } \\
\mathbf{1 9 7 6}\end{array}$ & Hab/km2 & $\begin{array}{c}\text { \% de } \\
\text { población } \\
\text { industrial }\end{array}$ \\
\hline Necochea & & Civil & 15,4 & 63,83 \\
\hline Ensenada & GLP & Armada & 409,1 & 57,69 \\
\hline Vicente López & GBA & Ejército & $500,1 \mathrm{y}+$ & 40,38 \\
\hline General San Martín & GBA & Ejército & $500,1 \mathrm{y}+$ & 27,58 \\
\hline Campana & & Prefectura & 58,9 & 27,18 \\
\hline Berazategui & GBA & Ejército & $500,1 \mathrm{y}+$ & 24,42 \\
\hline Tigre & GBA & Armada & $500,1 \mathrm{y}+$ & 24,28 \\
\hline Coronel Brandsen & & Civil & 13,6 & 22,20 \\
\hline Avellaneda & GBA & Ejército & $500,1 \mathrm{y}+$ & 21,83 \\
\hline San Isidro & GBA & Ejército & $500,1 \mathrm{y}+$ & 19,09 \\
\hline Luján & & Civil & 85,9 & 17,67 \\
\hline Berisso & GLP & Armada & 490,0 & 16,85 \\
\hline Tres de Febrero & GBA & Ejército & $500,1 \mathrm{y}+$ & 16,60 \\
\hline Lanús & GBA & Ejército & $500,1 \mathrm{y}+$ & 16,25 \\
\hline La Matanza & GBA & Ejército & $500,1 \mathrm{y}+$ & 15,81 \\
\hline Pilar & & Civil & 239,9 & 15,73 \\
\hline Esteban Echeverría & GBA & Fuerza Aérea & $500,1 \mathrm{y}+$ & 15,31 \\
\hline Baradero & & Civil & 17,2 & 14,19 \\
\hline Ramallo & & Ejército & 21,8 & 13,42 \\
\hline Quilmes & GBA & Ejército & $500,1 \mathrm{y}+$ & 13,07 \\
\hline Escobar & Civil & 293,8 & 12,58 \\
\hline Pergamino & Civil & 28,4 & 12,58 \\
\hline Promedio provincial & & $\mathbf{3 5 , 3}$ & $\mathbf{1 2 , 5 3}$ \\
\hline
\end{tabular}

Fuente: Elaboración propia en base a INDEC (1974, 1982).

Estos municipios se ubican en el GBA o el GLP, o en la zona ribereña del Paraná, con una alta o muy alta densidad poblacional y autoridades políticas militares o de las fuerzas de seguridad. Dichos rasgos se acentúan si se observa a los 11 distritos con más de 17\% de población industrial: Avellaneda, Beraza- 
tegui, Campana, Coronel Brandsen, Ensenada, General San Martín, Luján, Necochea, San Isidro, Tigre y Vicente López ${ }^{14}$.

Finalmente, el Mapa 7 muestra el vínculo existente entre el porcentaje de población asistente a nivel educativo superior o universitario ${ }^{15}$ y la procedencia de los intendentes bonaerenses:

\section{MAPA 7: POBLACIÓN QUE ASISTE A NIVEL EDUCATIVO SUPERIOR O UNIVERSITARIO (EN \%) Y PROCEDENCIA DE LOS INTENDENTES MUNICIPALES. PBA, 1976.}
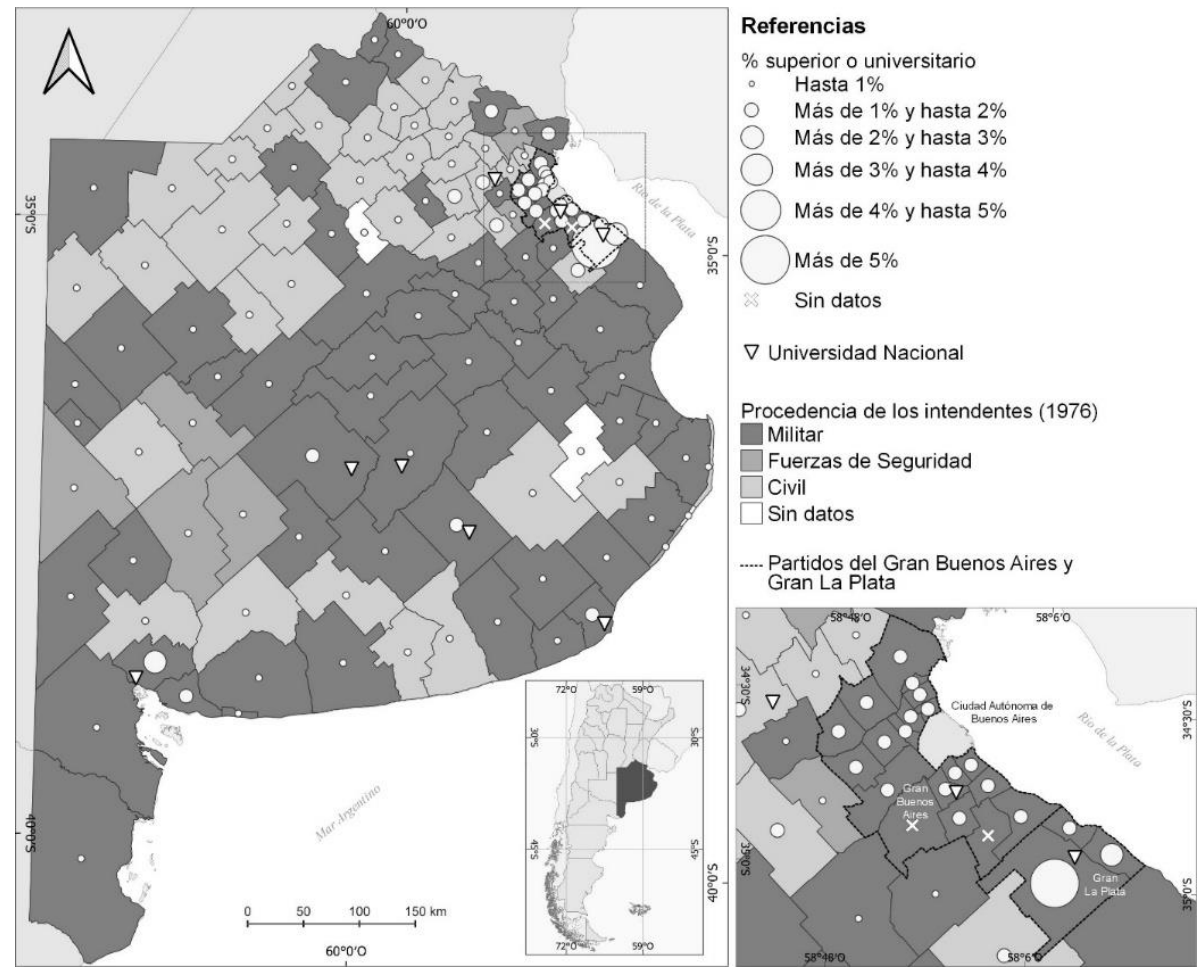

Nota: El Censo 1980 (INDEC, 1982) no desagrega por municipio del GBA los datos sobre esta variable educativa; a todos les fue asignado el valor promedio del conglomerado $-1,4 \%-$. Fuente: Elaboración propia en base a INDEC (1982).

El Mapa 7 muestra, en primer lugar, la asociación entre la distribución de este grupo poblacional -que en promedio era del 1,4\%- y la ubicación de alguna

\footnotetext{
${ }^{14}$ La excepción de Necochea, con el mayor \% de población industrial de toda la PBA $-63,83 \%-$, puede responder a que poseía poca población, pero con una PEA predominantemente ocupada en la industria pesquera.

${ }^{15}$ Se trata de uno de los pocos indicadores educativos discriminados por municipio en el Censo 1980 (INDEC, 1982, p. 83 y ss.).
} 
de las universidades nacionales con sede en la PBA: La Plata, Lomas de Zamora, Luján, Mar del Plata, la Universidad del Centro de la Provincia de Buenos Aires -Azul, Olavarría y Tandil- y la Universidad Nacional del Sur en Bahía Blanca. En segundo lugar, la elevada concentración de esta población en el territorio bonaerense. Los datos disponibles ${ }^{16}$ permiten identificar sólo cinco municipios con valores mayores al promedio provincial: La Plata, Bahía Blanca, Berisso, Ensenada y Tandil (Cuadro 2):

CUADRO 2: MUNICIPIOS CON \% DE POBLACIÓN EN NIVEL EDUCATIVO SUPERIOR O UNIVERSITARIO MAYOR AL PROMEDIO PROVINCIAL. PBA.

\begin{tabular}{|l|c|c|c|c|c|}
\hline Municipio & $\begin{array}{l}\text { GBA o } \\
\text { GLP }\end{array}$ & $\begin{array}{c}\text { Procedencia } \\
\text { intendente en } \\
\mathbf{1 9 7 6}\end{array}$ & Hab/km2 & $\begin{array}{c}\text { \% de } \\
\text { población } \\
\text { industrial }\end{array}$ & $\begin{array}{c}\text { \% de población } \\
\text { que asiste a } \\
\text { universitaria o } \\
\text { superior }\end{array}$ \\
\hline La Plata & GLP & Armada & 515,3 & 5,42 & 5,3 \\
\hline Bahía Blanca & & Armada & 101,8 & 8,02 & 2,6 \\
\hline Berisso & GLP & Armada & 490,0 & 16,85 & 2,3 \\
\hline Ensenada & GLP & Armada & 409,1 & 57,69 & 2,0 \\
\hline Tandil & & Ejército & 18,6 & 8,13 & 1,8 \\
\hline Promedio provincial & & & $\mathbf{3 5 , 3}$ & $\mathbf{1 2 , 5 3}$ & 1,4 \\
\hline
\end{tabular}

Fuente: Elaboración propia en base a INDEC (1982).

En este pequeño grupo predominan los municipios gobernados por la Armada, y la ubicación en el GLP, área de influencia de la Universidad Nacional de La Plata, con altas densidades de población. Asimismo, se destaca aquí Bahía Blanca, sede de la Universidad Nacional del Sur, donde además se ubicaba la Base Aeronaval Comandante Espora, entre otros organismos militares (Armada Argentina, 2021).

\section{CARACTERÍSTICAS GENERALES DE LA ELITE DE INTENDENTES BONAERENSES ENTRE 1976 Y 1983.}

Sobre el conjunto de todos los individuos que ocuparon por lo menos una vez el cargo de intendente bonaerense en algún momento de la dictadura 406-, sobresale la primacía de los civiles -66\%- sobre los militares -31\%-o los miembros de las fuerzas de seguridad $-3 \%-$. Entre los militares predominaba el

\footnotetext{
${ }^{16} \mathrm{La}$ ausencia de datos discriminados por municipio del GBA del Censo 1980 sobredimensiona unidades espaciales con altos valores de la variable que sí son desagregados por la fuente como, por ejemplo, La Plata.
} 
Ejército, con el $75 \%$ del total, frente al $15 \%$ de la Armada y el 10\% de la Fuerza Aérea (Canelo \& Kryskowski, 2021).

Estos funcionarios se distribuyeron en forma irregular en los distintos municipios (Mapa 8):

MAPA 8: PROCEDENCIA DEL CONJUNTO DE LOS INTENDENTES BONAERENSES, POR MUNICIPIO (1976-1983).

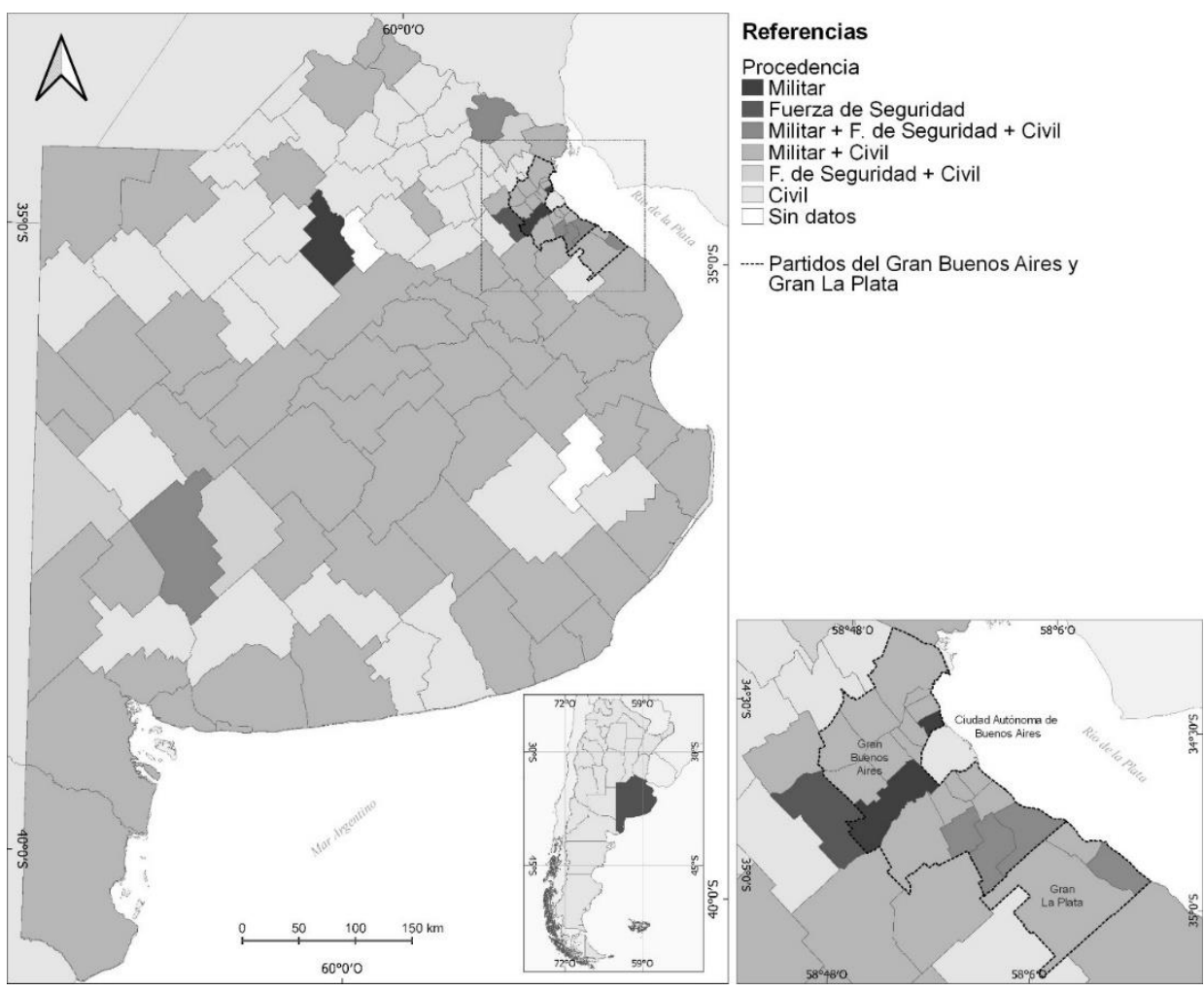

Fuente: Elaboración propia en base a Canelo y Kryskowski (2021).

El Mapa 8 muestra el predominio de situaciones mixtas, con alternancia entre autoridades militares, civiles y de las fuerzas de seguridad en cada municipio. Sólo hubo tres que fueron gobernados solo por militares durante toda la dictadura: La Matanza, Vicente López y Bragado. La Matanza y Vicente López comparten la pertenencia al GBA, alta densidad poblacional y un porcentaje de población industrial mayor al promedio provincial y sus intendentes poseen una jerarquía militar más alta que la del resto de los intendentes militares (Canelo \& Kryskowski, 2021). Bragado es una excepción que debe explicarse por razones locales: allí gobernó durante toda la dictadura el coronel Arturo Ibarra Negueloua, de familia 
bragadense conservadora con varios intendentes en su haber, único intendente militar de la dictadura con una inusual estabilidad en su cargo.

Sí fueron frecuentes los municipios gobernados solo por civiles durante toda la dictadura - por lo menos, fueron $29^{17}$, generalmente ubicados en el llamado interior bonaerense y con densidades de tipo rural, con excepción de Escobar y $\operatorname{Pilar}^{18}$.

La posesión de experiencia previa fue un atributo valorado en el reclutamiento de intendentes bonaerenses: el 23\% contaba con experiencia previa en el ejercicio del mismo cargo. La mayoría de los intendentes experimentados eran civiles, y había hecho su experiencia previa durante el gobierno peronista depuesto o durante la Revolución Libertadora -1955-1958- y/o en el transcurso de la Revolución Argentina (Canelo \& Kryskowski, 2021).

Finalmente, y a pesar de que la duración temporal del cargo de intendente no había sido contemplada explícitamente en la normativa autoritaria, las máximas autoridades políticas bonaerenses tuvieron una considerable estabilidad (Mapa 9).

Más de la mitad de los municipios de la PBA tuvo sólo entre dos y tres jefes municipales $-54,08 \%$ - Además del ya mencionado Bragado, los más estables fueron Navarro, Rauch, Puán, Pellegrini, General Alvear, San Pedro, Pila y Rivadavia; todos con baja densidad poblacional, baja presencia industrial y de población asistente a niveles educativos superiores, y gobernados por intendentes civiles, en general notables locales vinculados con ocupaciones agropecuarias (Canelo \& Kryskowski, 2021).

En contraste, hubo 6 municipios con alta inestabilidad, en términos de cantidad de intendentes: General Madariaga -nueve intendentes-, Lanús -ocho, Campana -siete-, y General Pueyrredón, Quilmes y Almirante Brown -seis-. En esta inestabilidad también parecen tener incidencia los factores estratégicos de la militarización: tres de estos municipios pertenecen al GBA y poseen muy alta densidad poblacional: Lanús, 10.377,33; Quilmes, 3.572,70; Almirante Brown, 2.720,65). Campana, Lanús, Quilmes y General Pueyrredón presentan un importante porcentaje de población industrial. Además, en este último partido, se ubicaban la Base Naval Mar del Plata y la Base Aérea Militar Mar del Plata, entre otras locaciones castrenses ${ }^{19}$.

\footnotetext{
${ }^{17}$ Ayacucho, Baradero, Coronel Brandsen, Capitán Sarmiento, Carlos Casares, Carmen de Areco, Chivilcoy, Colón, Coronel Pringles, De la Costa, Escobar, General Arenales, General Las Heras, Leandro N. Alem, Lincoln, Luján, Maipú, Mercedes, Navarro, Necochea, 9 de Julio, Pergamino, Pilar, Rivadavia, Salto, San Andrés de Giles, San Antonio de Areco, San Cayetano y San Pedro.

${ }^{18}$ La precariedad de datos disponibles no permite establecer si hubo municipios gobernados sólo por intendentes de las fuerzas de seguridad.

${ }^{19}$ La muy alta inestabilidad de General Madariaga, que no comparte las propiedades de este grupo
} 
MAPA 9: CANTIDAD DE INTENDENTES POR MUNICIPIO. PBA, 1976-1983.

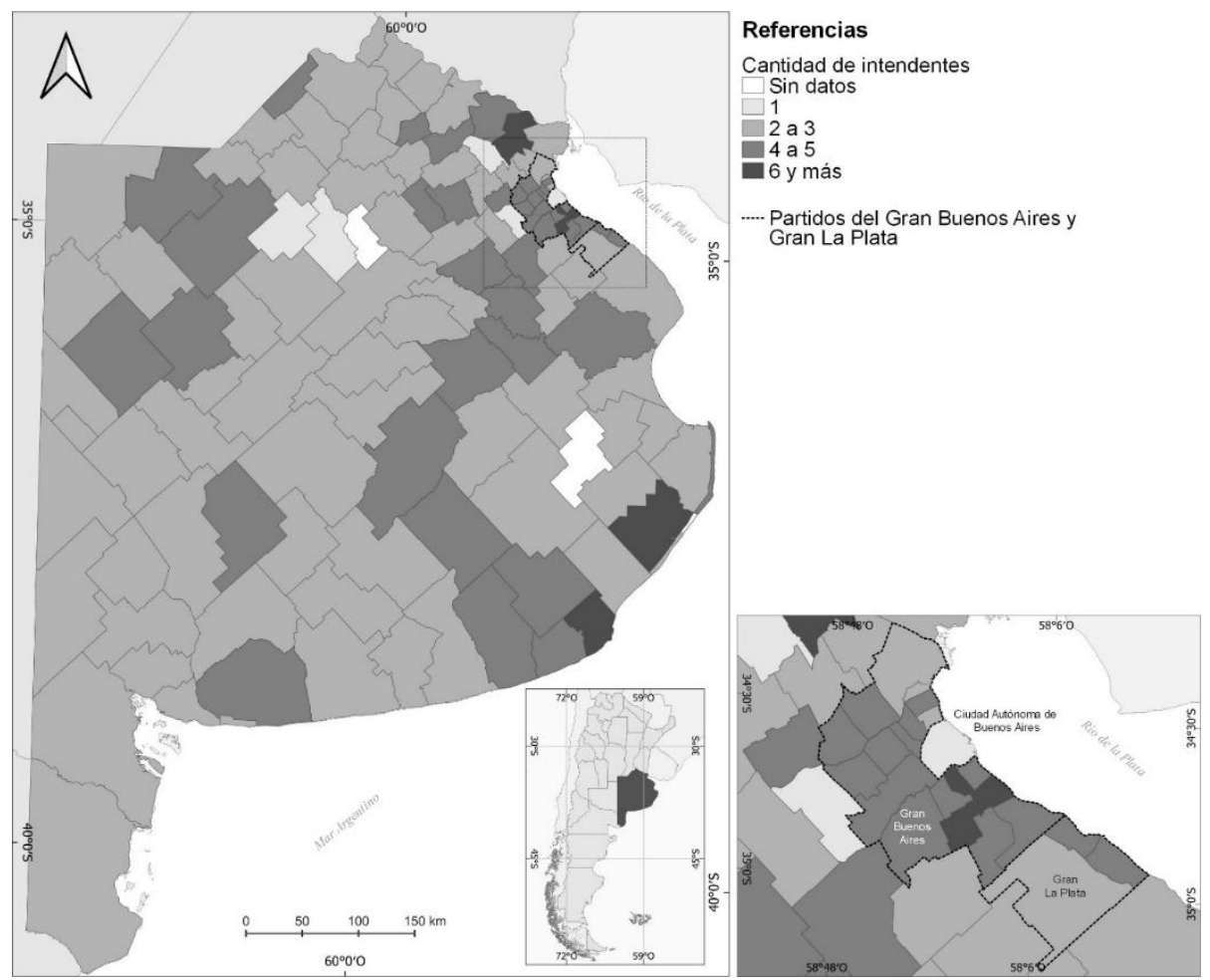

Fuente: Elaboración propia en base a Canelo y Kryskowski (2021).

\section{CONCLUSIONES}

Esta investigación muestra la inseparabilidad de los objetivos políticogubernamentales y los objetivos represivos de la última dictadura cívico-militar argentina en la designación de las más altas autoridades políticas de la PBA. Los municipios bonaerenses fueron piezas fundamentales en el tendido de una red capilar de control territorial y poblacional en una provincia clave para los planes refundacionales de la dictadura argentina. De allí que, como se ha mostrado, el reclutamiento de las más altas autoridades políticas locales fuera más cuidadoso de lo que podrían sugerir la complejidad y la heterogeneidad del caso.

de municipios, debe explicarse por factores específicos, probablemente vinculados por la presencia de un importante CCD en la Comisaría de General Madariaga, parte del circuito represivo de la Subzona 15, Área 152. 
En primer lugar, el presente trabajo muestra que en 1976 las máximas autoridades políticas de la PBA estuvieron mucho más militarizadas que el nivel nacional general, y que esta militarización fue cediendo paulatinamente, al compás de las necesidades políticas y burocráticas más amplias de la dictadura.

Los cambios en las más altas autoridades gubernamentales -presidente y gobernador- y militares -Comandos de Cuerpo-, el declive del escenario de la lucha contra la subversión y la aceleración de la convergencia-cívico militar, fueron factores que determinaron los cambios en la composición del poder político local de la PBA entre 1976 y 1983. Este proceso de militarización y desmilitarización posterior fue tan profundo que en poco más de siete años las Fuerzas Armadas -y también las de seguridad-pasaron de representar el $68 \%$ de los intendentes en 1976 al $4 \%$ en 1983.

En segundo lugar, el trabajo muestra que, en esta provincia considerada estratégica por la dictadura, la designación de las autoridades locales estuvo guiada por factores también estratégicos, vinculados con la lucha antisubversiva, y con los cambios en la construcción de un desquiciado escenario de confrontación contra un enemigo con métodos excepcionales, a los que había que oponerle otros, que además de excepcionales fueran eficientes para exterminarlo. Esto llevó a la ponderación de, al menos, tres factores estratégicos que fueron estudiados aquí: la densidad poblacional, el peso de los trabajadores industriales y el de la población asistente a niveles educativos superiores o universitarios.

La forma desigual en que se combinaron estos tres factores en cada uno de los municipios bonaerenses determinó su mayor o menor "peligrosidad subversiva", y a su vez la dinámica particular del reclutamiento de autoridades locales en cada caso, marcando una suerte de división del trabajo entre intendentes civiles y militares.

Los municipios más densamente poblados - aquellos considerados urbanos-, ubicados en el GBA y el GLP, con mayor porcentaje de población industrial y/o asistente a instituciones de educación superior o universitaria, o en cuyo territorio estuvieran ubicados importantes bases o destacamentos de alguna de las fuerzas, fueron, en general, entregados a intendentes militares o de las fuerzas de seguridad. Éstos fueron los municipios más militarizados, los más inestables -en términos de cantidad de intendentes-y los que sufrieron, también, el mayor peso de la feroz represión estatal característica del período. Muchos nunca fueron abandonados por los intendentes militares hasta la transición a la democracia.

En contraste, los municipios menos densamente poblados, ubicados en el interior de la $\mathrm{PBA}$, con bajo porcentaje de población industrial y/o poca presencia 
de población en instituciones de educación superior o universitaria fueron, en general, entregados a intendentes civiles, en muchos casos notables locales vinculados con actividades agropecuarias; incluso desde el principio de la dictadura, cuando la militarización del conjunto fue la regla. Estos espacios rurales, considerados de baja peligrosidad subversiva fueron los más estables en términos de presencia y reclutamiento de intendentes, y en los mismos hasta fue posible para muchos construir carreras políticas locales (Canelo \& Kryskowski, 2021).

En tercer lugar, este estudio mostró algunas tendencias centrales del reclutamiento del conjunto de los 406 intendentes de la PBA analizados aquí. El predominio civil $-66 \%$ del total general- distingue a este nivel de gobierno de otros más militarizados, como los ejecutivos a nivel nacional y provincial (Canelo, 2013, 2016), lo que está vinculado con las funciones políticas específicas que debían cumplir los intendentes para lograr esta mayor cercanía con las "fuerzas vivas de la comunidad" imaginada por el plan refundacional de la dictadura.

Además, se observa una distribución mixta de autoridades en estos espacios locales, donde se combinaron funcionarios de diversas procedencias; en general con experiencia previa en gestión municipal en el mismo distrito, que gozaron de mayor estabilidad que otros funcionarios en posiciones más altas de poder. Más de la mitad de los municipios bonaerenses no tuvo más que dos o tres intendentes en más de 7 años, siendo los más favorecidos en este sentido, nuevamente, los civiles al frente de municipios rurales.

\section{REFERENCIAS BIBLIOGRÁFICAS}

Águila, G. (ed.). (2017). Territorio Ocupado: La historia del Comando del II Cuerpo de Ejército en Rosario (1960-1990). EMR.

Águila, G., Garaño, S., \& Scatizza, P. (eds.). (2016). Represión estatal y violencia paraestatal en la historia reciente argentina. UNLP.

Araujo, M. P., Pimentel da Silva, I., \& dos Reis Santos, D. (eds.). (2013). Ditadura Militar e Democracia no Brasil: História, Imagem e Testemunho. Ponteio.

Armada Argentina. (2021). Ubicación y disposición de BASES y APOSTADEROS de la Armada entre 1976 y 1983. Dirección General de Organización y Doctrina de la Armada Argentina.

Ballester, G. (2014). Asociativismo y poder local: El caso de la Asociación Italiana de Ayuda y Socorros Mutuos Fraternidad y Unión en General Sarmiento durante la última dictadura argentina (1976-1983). Anuario digital de la Escuela de Historia, (26), 264-282. https://doi.org/10.35305/aeh.v0i26.160

Bohoslavsky, J. P. (2015). ¿Usted también, doctor? Complicidad de jueces, fiscales y abogados durante la dictadura. Siglo XXI. 
Bohoslavsky, E., Patto Sá Motta, R., \& Boisard, S. (eds.). (2019). Pensar as direitas na América latina. Alameda.

Canelo, P. (2013). Construyendo elites dirigentes. Los gobernadores provinciales durante la última dictadura militar (Argentina, 1976-1983). Anuario del Centro de Estudios Históricos "Prof. Carlos S. A. Segreti", (11), 323-341.

Canelo, P. (2016). La política secreta de la última dictadura argentina. Prometeo.

Canelo, P. (2019). El guerrero y el técnico. Albano Harguindeguy y su relato sobre la represión y los desaparecidos (Argentina, 1976-2012). Sociohistórica, (43), e077. https://doi.org/10.24215/18521606e077

Canelo, P., \& Ippolito-O'Donnell, G. (2018). Regime Archives. The Argentine Case. In J. Kozák, N. Maráková, M. Oplíštilová \& P. Žáček (eds.), Memory of Nations. Democratic Transition Guide (pp. 25-32). National Endowment for Democracy; Institut CEVRO.

Canelo, P., \& Kryskowski, P. (2021). 'Una nueva clase dirigente'. Los intendentes bonaerenses durante el Proceso de Reorganización Nacional en Argentina. Íconos. Revista de Ciencias Sociales, (71), 195-212. https://doi.org/10.17141/iconos.71.2021.4765

Carnovale, V. (2011). Los combatientes: Historia del PRT-ERP. Siglo XXI.

Castiglione, M. (1992). La militarización del Estado en la Argentina (1976-1981). CEAL.

Catoira, M. (2013). Gobierno y funcionarios municipales en General Sarmiento durante la última dictadura. I Jornadas de Problemas de Historia Reciente del Conurbano Bonaerense Norte y Noroeste.

Comando General del Ejército. (1975). Directiva del Comandante General del Ejército N ${ }^{\circ} 404 / 75$ (lucha contra la subversión), octubre de 1975.

Confino, H. (2015). La contraofensiva estratégica montonera en las memorias de sus participantes: Crónica de un objeto polémico. Aletheia, (11), 1-22.

Crenzel, E. (2014). La historia política del Nunca más: La memoria de las desapariciones en la Argentina. Siglo XXI.

Da Silva Catela, L., \& Jelin, E. (eds.). (2002). Los archivos de la represión: Documentos, memoria y verdad. Siglo XXI.

D’Andrea Mohr, J. L. (1999). Memoria Devida. Colihue.

EMGE (Estado Mayor General del Ejército). (1977). La subversión en la Argentina, cit. en La Nación, 20/4/1977.

Feld, C., \& Salvi, V. (eds.). (2019). Las voces de la represión: Declaraciones de perpetradores de la dictadura argentina. Miño \& Dávila.

Franco, M. (2012). Un enemigo para la Nación: Orden interno, violencia y "subversión”, 1973-1976. FCE.

Frontalini, D., \& Caiati, M. C. (1984). El mito de la guerra sucia. CELS

González Bombal, I. (1988). Los vecinazos: Las protestas barriales en el Gran Buenos Aires, 1982-1983. IDES.

González Bombal, I. (2015). La cría del Proceso: Política local en el conurbano durante la dictadura militar. In G. Kessler (ed.), El gran Buenos Aires (pp. 343-364). Unipe; Edhasa. 
Grupo La Plata. (1976). Un nuevo ciclo histórico argentino: Del Proceso de Reorganización Nacional a la Tercera República. S/D. Octubre de 1976.

INDEC (Instituto Nacional de Estadística y Censos). (1974). Censo Nacional Económico 1974: Industria. Resultados Definitivos. INDEC.

INDEC (Instituto Nacional de Estadística y Censos). (1982). Censo Nacional de Población y Vivienda 1980. Serie B. Características generales. PBA-República Argentina. INDEC.

Jensen, S., \& Lastra, S. (eds.). (2014). Exilios: militancia y represión. Nuevas fuentes y nuevos abordajes de los destierros de la Argentina de los años setenta. EDULP. https://doi.org/10.35537/10915/91119

Lvovich, D. (2010). Burócratas, amigos, ideólogos y vecinalistas: El reclutamiento de funcionarios municipales de Morón durante la dictadura militar (1976-1983), In E. Bohoslavsky \& G. Soprano, G. (eds.), Un Estado con rostro humano (pp. 411-430). UNGS-Prometeo.

Marchesi, A. (2009). 'Una parte del pueblo feliz, contento, alegre': Los caminos culturales del consenso autoritario durante la dictadura. In C. Demasi et. al. (eds.), La dictadura civicomilitar. Uruguay, 1973-1985 (pp. 323-394). Ed. de la Banda Oriental.

Markarian, V. (2006). Idos y recién llegados: La izquierda uruguaya en el exilio y las redes transnacionales de derechos humanos, 1967-1984. Correo del Maestro; Ediciones La Vasija.

McSherry, P. (2005). Predatory states: Operation Condor and covert war in Latin America. Rowman \& Littlefield.

Mignone, E. F. (1991). Derechos Humanos y Sociedad. El caso argentino. Colihue.

Mignone, E. F., \& Conte McDonnell, A. (2006). Estrategia represiva de la dictadura militar. La doctrina del 'paralelismo global'. Colihue.

Mittelbach, F., \& Mittelbach, J. (2000). Sobre Áreas y Tumbas. Informe sobre desaparecedores. Sudamericana.

Morresi, S. (2019). Reconocer lo actuado: El liberalismo conservador y sus miradas sobre la dictadura y la violencia (1982-1989). Revista de Historia Americana y Argentina, (2), 223-254.

Muleiro, V. (2011). 1976: El golpe civil. Planeta.

OCDE (Organización para la Cooperación y el Desarrollo Económicos). (2011). OECD Regional Typology. Directorate for Public Governance and Territorial Development. OCDE. https://www.oecd.org/cfe/regionaldevelopment/OECD_regional_typology_Nov2012.pdf

O’Donnell, G. (1997). Contrapuntos. Paidós.

Rodríguez, L. G. (2009). Descentralización municipal, intendentes y ‘fuerzas vivas' durante el Proceso (1976-1983). Cuestiones de Sociología, (5-6). https://www.cuestionessociologia.fahce.unlp.edu.ar/article/view/CSn5-6a18/5213

Rollemberg, D., \& Viz Quadrat, S. (2010). A construção social dos regimes autoritários. Civilização Brasileira.

Scocco, M., Divinzenso, M. A., \& Kahan, E. (2021). Violencia política en el siglo XX. Actas del III Coloquio Internacional sobre Violencia Política en el Siglo XX y IV Jornadas de Trabajo de la RER. HyA ediciones.

Valdivia Ortiz de Zárate, V., Alvarez Vallejos, R., \& Donoso Fritz, K. (2012). La alcaldización de la politica: Los municipios en la dictadura pinochetista. LOM. 
Vicente, M. (2015). De la refundación al ocaso: Los intelectuales liberal-conservadores ante la última dictadura. UNLP; Universidad Nacional de Misiones; UNGS.

Viz Quadrat, S. (ed.). (2011). Caminhos Cruzados: História e memória dos exílios latino-americanos no século XX. FGV.

Yaffé, J. (2012). La dictadura uruguaya (1973-1985): Nuevas perspectivas de investigación e interpretación historiográfica. Estudios Ibero-Americanos, (38), 13-26. https://doi.org/10.15448/1980-864X.2012.1.11583

Yannuzzi, M. A. (1996). Politica y dictadura: Los partidos políticos y el Proceso de Reorganización Nacional. 1976-1982. Fundación Ross. 